\title{
Level of State Anxiety among Youth Football Players According Different Playing Positions
}

\author{
Kenioua Mouloud' \\ 'University of Ouargla, Institute of Physical Education and Sport, Ouargla, Algeria
}

\begin{abstract}
The aim of the study was to examine and describe the level of state anxiety among football players according different playing positions. The research group consisted 61 male youth football players (goalkeepers, defenders, midfielders and (forwards) attackers) of age ranged from 16 to 19, from Fanzeres Academy -city of Porto Portugal-The subjects were randomly selected and were categorized by their playing positions. The Competitive State Anxiety Inventory-2 (CSAl-2) was used to collect data, sport-specific state anxiety scale, the CSAI-2 was developed to Portuguese version. Descriptive statistics, kruskal-wallis Test and spearman's correlation analysis were used to calculate data. The results showed that there was above moderate level of state anxiety among youth football players and no significant difference in state anxiety among youth football players according playing positions. It is essential that coaches and sport psychologists develop strategies to identify the state anxiety of youth football players in order to enhance their performance.
\end{abstract}

Key words: state anxiety, football players, playing position

\section{Introduction}

Athletes and coaches often use the words "anxiety", "stress" and "arousal" interchangeably and because their listeners generally know what they are trying to say it does not lead to miscommunication. Precision is needed. Anxiety refers to the levels of perceived threat i.e., accompanied by worry nervousness and apprehension. A key idea in anxiety is athletes' interpretation of the danger to their wellbeing. Sometimes anxiety is a normal response to real threats, such as when individuals are confronted by an armed person. Sometimes anxiety involves an exaggerated response to in imagined threat, such as my reaction to spiders (except in Australia where they can kill you!). Anxiety is typically accompanied by high arousal, but the two are not the same. People can be highly aroused yet not anxious such as when athletes win major competitions (Tod, 2014).

Spielberger $(1966,1972)$ further noted that for a theory of anxiety to be an adequate it must differentiate as a mood state and as personality trait. additionally, it must differentiate among the stimulus conditions antecedent to these forms of anxiety. Spielberger (1966) proposed the state-trait theory of anxiety, which differentiates between state and trait anxiety. State anxiety (A-state) is defined as an emotional state "characterized by subjective, consciously perceived feelings of apprehension and tension, accompanied by or associated with activation or arousal of the autonomic nervous system". This condition varies from moment to moment and fluctuates proportional to the perceived threat in the immediate situation. Trait anxiety (A-trait), on the other hand, is "a motive or acquired behavioural disposition that predisposes an individual to perceive a wide range of objectively non-dangerous circumstances threatening and to respond to these with state anxiety reactions disproportionate in intensity to the magnitude of the objective danger". The state-trait theory of anxiety predicts that high-trait-anxious individuals will perceive more situations as threatening and react with greater state anxiety in a greater variety of situations than low-trait-anxious individuals. Adopting a multidimensional approach, Martens, Vealey

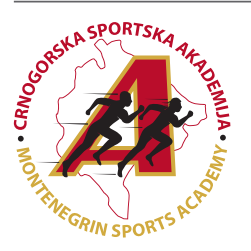

Correspondence:

K. Mouloud

University of Ouargla, Institute of Physical Education and Sport, Ouargla, Algeria

E-mail: moukenioua@gmail.com 
and Burton (1990) proposed that cognitive anxiety, somatic anxiety and self-confidence each had different relationships with performance. Performance was predicted to have a negative relationship with cognitive anxiety (increase in cognitive anxiety is associated with decrease in performance). Somatic anxiety was hypothesized to have an Inverted-U (Inverted-U theory 1908) relationship with performance. self-confidence was predicted to have a positive relationship with performance (increased self-confidence is associated with improved performance). Along with proposing the multidimensional anxiety theory, Martens also published the Competitive State Anxiety Inventory-2 (CSAI2) to help researchers test the model's predictions. In sport, anxiety plays an important role on deteriorate athlete's performance (Cox, Qiu, \& Liu,1993; Raglin \& Hanin, 2000; Ortiz, 2006). Athletes realized the influence of anxiety in determining win or lose (Sanderson,1989).

Football is a team sport. In order to succeed, it is necessary for highly specialized players in specific positions and tasks to help one another. For a successful soccer team; each player should be trained not only for conditional attributes like endurance, strength, speed or agility but also should be trained technically and tactically. In accordance with that, each player should have different physical, physiological and psychological attributes depending on his/her playing position (Akın, Kireker, \& Koklu, 2009; Pivovarnicek, Pupis, \& Lacena, 2015). Although there are some studies showing that psychological factors like concentration, competition anxiety, anger style, anger management, self-image, self-esteem can affect player's playing style and injury risk, they do not seem to be enough in number (Kurt, Catikkas, Omurlu, \& Atalay, 2012; Martinez-Rodriguez, Chicoy-Garcia, Leyva-Vela, Martinez-Hernandez, \& Manzanares Serrano, 2017).

A study conducted by Allie, Larson, and DeBeliso (2018) on levels of anxiety among North American football players. The purpose of the study was to determine if anxiety level differs between NCAA Division 1 North American football players based on position played and determine intra-individual and inter-position differences in anxiety level prior to a scrimmage versus a practice scenario. The results showed that $63.9 \%$ of players have average anxiety and no statistical differences in anxiety categories were found between positions or between the practice and the scrimmage. Another study conducted by Suleiman and Rao (2016) on competitive anxiety level of Ethiopian male football players and its impact on their performance. The descriptive Statistical analysis indicates that they were at the "average level" of competitive anxiety. The ANOVA result shows that there was no significant difference in competitive anxiety among the group of players across their playing position. A study conducted by Vincent and Yahaya (2013) on cognitive and somatic anxiety among football players of different ethnics' groups in Malaysia. The result showed that Malay ethnic categories exhibited as higher levels of cognitive anxiety, whereas Indian ethnic exhibit a higher level of somatic anxiety.

The aim of this study was to know the level of state anxiety among football players as well as to investigate the cognitive anxiety, somatic anxiety and self-confidence among football players in different playing positions. Perhaps most importantly, the study operationalized and included some new variables (youth football players ranging from 16 years to 19 years and playing different positions - goalkeepers, defenders, midfielders and forwards). The research study questions were as follows:

QUE.1 Is there high level of state anxiety among youth football players?

QUE.2 Is there significant difference in state anxiety among youth football players according playing position?

\section{Methods}

Participant

The study consisted 61 football players from Fanzeres Academy - city of Porto Portugal. The ages of players ranged between 16 and 19 years with a mean age of $16.77 \pm 1.05$ years. On average, the players had played for $7.97 \pm 2.43$ years. A large number $\mathrm{N}=21$ (34.4\%) of the players were defenders, followed by midfielders $\mathrm{N}=18$ (29.5\%), forwards $\mathrm{N}=16$ (26.2\%), and goal keepers $\mathrm{N}=6(9.8 \%)$.

\section{Procedure}

The clearance was obtained from the president of team prior to all study procedures. The test took place in a Hall Meetings on sport complex. participants provided informed consent. Then, they were provided with a questionnaire package and asked to respond to each question as honestly as possible. Coach with me remained nearby to answer any questions that arose during testing (in Portuguese language). The questionnaire package took approximately 15-20 minutes and was administered to the participants approximately 1 hour before competition.

\section{Data analyses}

Descriptive statistics was computed to characteristics the entire sample of football players, and to know level of state anxiety and Kruskal Wallis Test was used to explore the differences of Football players' state anxiety according to their playing position.

\section{Instrument}

The Competitive State Anxiety Inventory-2 (CSAI-2) was used to collect data, sport-specific state anxiety scale developed by Martens et al. (1990). The scale divides anxiety into three components: cognitive anxiety, somatic anxiety, and a related component-self-confidence. To score the CSAI-2, take all the scores for each item at face value with the exception of item 14, where you "reverse" the score. For e.g., if you circled 3 , count that as 2 points $(1=4 ; 2=3 ; 3=2 ; 4=1)$. Total scores in the following manner: Cognitive state anxiety: Sum items 1, 4 , $7,10,13,16,19,22$, and 25 . Somatic state anxiety: Sum items $2,5,8,11,14,17,20,23$, and 26. Self-confidence: Sum items 3, $6,9,12,15,18,21,24$, and 27 . The scores for each will range from 9 to 36 , with 9 indicating low anxiety (confidence) and 36 indicating high anxiety confidence.

The CSAI-2 was developed by Cruz et al. (2006) to Portuguese version. It was formed also same dimensions but with a reduction to 22 items s (Cognitive state anxiety: sum: 1, 4, 6, $9,12,15,18$, and 21. Somatic state anxiety: Sum items, 2, 7, 10, 13,16 , and19. Self-confidence: Sum items, 3, 5, 8, 11, 14, 17, 20, and 22.). In present study reliability and validity of Competitive State Anxiety Inventory-2 (CSAI-2) were done.

\section{Results}

Level of state anxiety

Findings related to the level of state anxiety among football players are shown in Table 1. 
Table 1. Shows level of state anxiety among football player $(\mathrm{N}=61)$

\begin{tabular}{lcc}
\hline \multicolumn{1}{c}{ Items of scale } & Mean & Std. Dev. \\
\hline 1. I'm worried about this game & 2.95 & 0.948 \\
2. I feel restless & 2.29 & 0.837 \\
3. I feel comfortable & 3.24 & 0.783 \\
4. I'm worried because I may not play good in this game & 2.68 & 1.068 \\
5. I feel self-confident & 3.08 & 0.816 \\
6. I'm worried because I might have lost the game & 2.93 & 0.946 \\
7.I feel tension in my stomach & 1.92 & 0.881 \\
8. I feel safe & 3.16 & 0.840 \\
9. I'm worried that I might fail under the pressure of competition & 2.68 & 0.988 \\
10. I feel my body relaxed & 3.08 & 0.829 \\
11. I am confident that I can respond to the challenge that is set to me & 3.23 & 0.789 \\
12. I am worried that you may have poor performance & 2.64 & 1.141 \\
13. My heart is beating very fast & 2.15 & 1.053 \\
14. I am confident that I will have a good performance & 3.23 & 0.673 \\
15. I am concerned that I may not achieve my objective & 2.66 & 1.044 \\
16. I feel my stomach "around" & 1.89 & 0.950 \\
17. I feel mentally relaxed & 3.08 & 0.869 \\
18. I am concerned that others may be disappointed with my performance & 2.36 & 1.033 \\
19. My hands are cold and wet & 1.62 & 0.934 \\
20. I am confident because I mentally imagine myself to achieve my goal & 3.16 & 0.772 \\
21. I am worried that I may not be able to concentrate & 2.33 & 1.044 \\
22. I am confident that I can overcome obstacles under the pressure of competition & 3.20 & 0.840 \\
\hline
\end{tabular}

In Table 1 , the average scores of state anxiety among football players for each item are given. It may be observed that football players had above average scores in total $(\mathrm{M}=2.71)$, remarkably, they scored lower on the nineteenth $(M=1.62)$ and higher on the eleventh and the fourteenth $(M=3.40)$.

In Table 1, the average scores of state anxiety among football players for each item are given. It may be observed that football players had above average scores in total $(M=2.71)$, remarkably, they scored lower on the nineteenth $(\mathrm{M}=1.62)$ and higher on the eleventh and the fourteenth $(\mathrm{M}=3.40)$.

State anxiety among football players according playing positions Football players' state anxiety was also examined according to their playing position as indicated in Table 2.

Table 2. Shows comparison of Football players' state anxieties according to their playing position

\begin{tabular}{|c|c|c|c|c|c|c|}
\hline Scale & Dimension & Position & $\mathbf{N}$ & Mean & Std. Dev. & Sig. \\
\hline \multirow{15}{*}{$\begin{array}{c}\text { State } \\
\text { anxiety }\end{array}$} & \multirow{5}{*}{$\begin{array}{c}\text { Cognitive state } \\
\text { anxiety }\end{array}$} & Goalkeeper & 6 & 2.77 & 0.768 & \multirow{5}{*}{0.751} \\
\hline & & Defender & 20 & 2.56 & 0.801 & \\
\hline & & Midfielder & 19 & 2.76 & 0.604 & \\
\hline & & Forward & 16 & 2.63 & 0.794 & \\
\hline & & Total & 61 & 2.68 & 0.741 & \\
\hline & \multirow{5}{*}{$\begin{array}{c}\text { Somatic state } \\
\text { anxiety }\end{array}$} & Goalkeeper & 6 & 1.86 & 0.340 & \multirow{5}{*}{0.751} \\
\hline & & Defender & 20 & 2.19 & 0.704 & \\
\hline & & Midfielder & 19 & 2.20 & 0.540 & \\
\hline & & Forward & 16 & 2.14 & 0.510 & \\
\hline & & Total & 61 & 2.09 & 0.523 & \\
\hline & \multirow{5}{*}{ Self-confidence } & Goalkeeper & 6 & 2.76 & 1.123 & \multirow{5}{*}{0.571} \\
\hline & & Defender & 20 & 3.18 & 0.595 & \\
\hline & & Midfielder & 19 & 3.12 & 0.387 & \\
\hline & & Forward & 16 & 3.40 & 0.414 & \\
\hline & & Total & 61 & 3.11 & 0.909 & \\
\hline
\end{tabular}

In Table 2, the average scores of state anxiety dimensions among football players are given. It may be observed that football players had higher average scores $(\mathrm{M}=3.11)$ in self-confidence dimension, remarkably, they scored lower average scores $(M=2.09)$ in somatic state anxiety dimension and they had average scores (2.68) cognitive state anxiety dimension.
Kruskal-Wallis Test was used also to compare football players' state anxiety according to playing position. The comparison analysis demonstrates that there were no significant differences $(\mathrm{p}>0.5)$ between cognitive state anxiety, somatic state anxiety and self-confidence. 


\section{Discussion}

The study, which was carried out to determine the level of state anxiety among football players, revealed some important information and results. As results of this study, it was concluded that the football players had above moderate level of state anxiety although the youth players belong to amateur team. The mental component, typically termed cognitive anxiety, is closely related to worry and deals with 'negative expectation and cognitive concerns about oneself, the situation at hand and potential consequences' (Morris, Davis, \& Hatchings, 1981). Athletes can develop cognitive anxiety because of their inability to perform or fear of performance failure. Athletes also have the tendency to worry the negative evaluation of their schoolmate, teachers, friends, fans, which can cause the level of cognitive anxiety increase. As well as somatic anxiety refers to athletes' changes in their physiology, such as increased perspiration, difficulty in breathing, increased heartbeat, changes in the brain wave, elevated blood pressure, increased urination, butterflies in the stomach, less saliva in the mouth and muscle tension. The sympathetic nervous system is stimulated by fear perception in the cerebral cortex, prompting an immediate stress response. Athletes, who have learned anxiety management skills, often respond to a greater degree to anxiety symptom but return to their resting rate sooner than those athletes, who are not trained in anxiety management (Vincent \& Yahaya, 2013). This result corresponds to the findings of (Turksoy, Bayansalduz, Altinici, \& Atikir, 2012; Zeng, 2003; Allie et al., 2018).

The results were concluded that no significant difference was found when comparing football players' state anxiety according the playing positions. This finding is inconsistent with the results of other investigations (Kirkcaldy, 1982; Andrew, Grobbelaar, \& Potgieter, 2007; Eloff, Monyeki, \& Grobbelaar, 2011). Kirkcaldy (1982) for example, found that players in defensive positions in soccer showed higher emotional stability than players in attacking positions. Another probable reason for inconsistency between the current findings and those stemming from earlier research was the young age of the participants. McCarthy, Jones, Harwood and Olivier (2010) postulated that young sport participants have less approximations of psychological skill usage compared to adult participants. The mean age of the sample in the present study was $16.77 \pm 1.05$ years old, which could be attest to insignificant relationship noticed between psychological skills and playing positions. Jooste, Steyn and Van den Berg (2014) support this view by conceding that athletes in the specialization stage (mean age $16.2 \pm 1.13$ years) may be at the ideal "windows of opportunity" for developing adult-like attributes and should, therefor, not be compared to older athlete's groups. In fact, the current study failed to concur with other investigations could be explained by the amateur level of participation of the sample tested in the present study. The results of the present study suggest that youth football players competing at amateur level they had homogeneously some psychological characteristics regardless of their respective position in the team. This finding, pertinent to soccer players, is corroborated by Kurt et al. (2012) who credited such homogenous results to the similar status (amateur/ professional) of the participants. As well as the results of study is consistent with results of (Allie et al., 2018; Suleiman \& Rao, 2016).

In conclusion, when making literature reviews, as parallel with many researches, present study was inconsistent with studies and consistent with others. The findings indicated there was above moderate level of state anxiety among youth football players. And the different playing positions were compared in term of state anxiety, there was no significant difference in state anxiety among football players according playing positions. Can be said that this situation is largely related to the groups having similar status (amateur), similar age and football experience. Future qualitative research which covers the test having multi-variables on state anxiety and others psychological characteristics could be performed. And suggesting a program to decrease state anxiety among football players.

\section{Acknowledgements}

There are no acknowledgements.

\section{Conflict of Interest}

The authors declare that there are no conflicts of interest.

Received: 01 January 2019 | Accepted: 23 January 2019 | Published: 01 February 2019

\section{References}

Akın, M., Kıreker, D., \& Koklu, Y. (2009). Comparison of 16-Year-Old Group Professional League Soccer Players Some Physical Characteristics in Terms of Their League Level and Positions. Turkiye Klinikleri Journal of Sports Sciences, 1(2), 72-18.

Allie, J., Larson, A., \& DeBeliso, M. (2018). Levels of anxiety: Practice vs. competition in NCAA Division I North American football players. International Journal of Sports Science, 8(4), 118-123. doi: 10.5923/j. sports.20180804.02.

Andrew, M., Grobbelaar, H.W., \& Potgieter, J.C. (2007). Sport Psychological Skill Levels and Related Psychological Factors That Distinguish between Rugby Union Players of Different Participation Levels. South African Journal for Research in Sport, Physical Education and Recreation, 29(1), 1-14. http://dx.doi.org/10.4314/sajrs.v29i1.25951.

Cox, R.H., Qiu, Y., \& Liu, Z. (1993). Overview of sport psychology. In R.N. Singer, M. Murphey and L.K. Tennant, Handbook of research on sport psychology. New York: Macmillan.

Cruz, J.F., Viveiros, M.I., Alves, L.A., Gomes, A.R., Matos, D., Ferreira, M.J., \& Dias, C. (2006). Psychometric characteristics of a Portuguese version of "Competitive State Anxiety Inventory-2" (CSAI-2): Preliminary data on its validity and structure factorial. In N. Santos, M. Lima, M. Melo, A. Candeias, M. Grácio and A. Calado (Eds.), Proceedings of the VI National Research Symposium in Psychology, 3, 104-125. Department of Psychology, University of Évora (in Portuguese).

Eloff, M., Monyeki, M.A., \& Grobbelaar, H.W. (2011). Mental skill levels of South African male student field hockey players in different playing positions. African Journal for Physical, Health Education, Recreation and Dance, 17(4),636-646.

Jooste, J., Steyn, B.J.M., \& Van den Berg, L. (2014). Psychological skills, playing positions and performance of African youth soccer teams. South African Journal for Research in Sport, Physical Education and Recreation, 36(1), 85100.

Kirkcaldy, B.D. (1982). Personality and sex differences related to positions in team sports. International Journal of Sport Psychology, 13, 141-153.

Kurt, C., Çatikkas, F., Omurlu, I..K., \& Atalay, O. (2012). Comparison of Loneliness, Trait Anger-Anger Expression Style, Self-esteem Attributes with Different Playing Position in Soccer. Journal of Physical Education \& Sport, 12(1),39-43. doi:10.7752/jpes.2012.01007.

Martens, R., Vealey, R.S., \& Burton, D. (1990). Competitive anxiety in sport Champaign, IL: Human Kinetics.

Martínez-Rodríguez, A., Chicoy-García, I., Leyva-Vela, B., Martínez-Hernandez, M., \& Manzanares Serrano, A. (2017). Could low fat mediterranean diet improves competitive anxiety in young sailors? Cross sectional study according to the STROBE statement. Cuadernos de Psicología del Deporte, 17(3), 95-104. http://revistas.um.es/cpd/article/view/313871 (in spanish)

McCarthy, P.J., Jones, M.V., Harwood, C.G., \& Olivier, S. (2010). What do young athletes implicitly understand about psychological skills? Journal of Clinical Sport Psychology, 4, 158- 172.

Morris, L., Davis, D., \& Hutchings, C. (1981). Cognitive and Emotional Components of Anxiety: Literature Review and Revised Worry-Emotionality Scale. Journal of Educational Psychology, 73, 541-555. 
Ortiz, J. (2006). Efficacy of relaxation techniques in increasing sport performance in women golfers. The Sport Journal, 9(1).

Pivovarnicek, P., Pupis, M., \& Lacena, M. (2015). A level of jump abilities of elite Slovak soccer players at different positions in field. Journal of Physical Education and Sport, 15(1), 53-56. doi:10.7752/jpes.2015.01009

Raglin, J.S., \& Hanin, Y.L. (2000). Competitive anxiety. In Yuri, L.H., Emotions in Sport. Champaign, IL: Human Kinetics.

Sanderson, F.H. (1989). Analysis of anxiety levels in sports. In Dieter Hackfort and Charles D. Spielberger, Anxiety in sports. New York: Hemisphere.

Spielberger, C.D. (1966). Theory and research on anxiety. in C.D. Spielberge (Ed). Anxiety and behavior (3-22). New York: academic press.

Spielberger, C.D. (1972). Anxiety as an emotional state. In C.D. Spielberger (Ed). Anxiety: current trends in theory and research (24-54). New York: academic press.
Suleiman, S., \& Rao, R.R. (2016). Competitive anxiety level of Ethiopian male football players and its impact on their performance. International Journal of Applied Research, 2(4), 318-320.

Tod, D. (2014). Sport psychology the basics (1st Ed.). New York: Routledge. Turksoy, A., Bayansalduz, M., Altinici, E.E., \& Atikir, A. (2012). Comparison of Pre and Post-Anxiety Levels of Volleyball Players aged 11-14. International Journal of Academic Research, 4(1), 143-147.

Vincent, A., \& Yahaya, M. (2013). Cognitive and somatic anxiety among football players of different ethnics' groups in Malaysia. Procedia - Social and Behavioral Sciences, 85, 258-266. https://www.sciencedirect. com/science/article/pii/S1877042813024841.

Zeng, H.Z. (2003). The Differences between Anxiety and Self-Confidence between Team and Individual Sports College Varsity Athletes. Interna tional Sports Journal, 7(1), 28. 